\title{
Proteoform-selective imaging of tissues using mass spectrometry
}

\author{
Manxi Yang ${ }^{[a]}$, Hang Hu ${ }^{[a]}$, Pei Su ${ }^{[a, b]}$, Paul M. Thomas ${ }^{[b]}$, Jeannie M. Camarillo ${ }^{[b]}$, Joseph B. Greer ${ }^{[b]}$, \\ Bryan P. Early ${ }^{[b]}$, Ryan T. Fellers ${ }^{[b]}$, Neil L. Kelleher ${ }^{*[b]}$, Julia Laskin ${ }^{*[a]}$
}

[a] M. Yang, H. Hu, P. Su, Dr. J. Laskin

Department of Chemistry, Purdue University

560 Oval Drive, West Lafayette, IN 47907 (USA)

E-mail: jlaskin@purdue.edu

[b] P. M. Thomas, J.M. Camarillo, B. P. Early, R. T. Fellers, J. B. Greer, P. Su, Dr. N. L. Kelleher

Departments of Chemistry and Molecular Biosciences, Northwestern University

2145 Sheridan Road, Evanston, IL, 60208 (USA)

Supporting information for this article is given via a link at the end of the document.

\begin{abstract}
Unraveling the complexity of biological systems relies on the development of new approaches for spatially resolved proteoformspecific analysis of the proteome. Herein, we employ nanospray desorption electrospray ionization mass spectrometry imaging (nano$D E S I M S I)$ for the proteoform-selective imaging of biological tissues. Nano-DESI generates multiply charged protein ions, which is advantageous for their structural characterization using tandem mass spectrometry (MS/MS) directly on the tissue. Proof-of-concept experiments demonstrate that nano-DESI MSI combined with ontissue top-down proteomics is ideally suited for the proteoformselective imaging of tissue sections. Using rat brain tissue as a model system, we provide the first evidence of differential proteoform expression in different regions of the brain.
\end{abstract}

A proteome is a collection of proteins expressed by an organism, which determines its biological state. Post-translational modifications (PTM) of proteins is a process that dramatically increases the complexity of the proteome beyond what can be predicted based on the known protein-coding genes. ${ }^{[1][2]}$ PTMs affect protein structure, interactions, transport, and function thereby exhibiting a pronounced effect on cell physiology. ${ }^{[3]}$ Furthermore, the reversible nature of PTMs facilitates the dynamic response of biological systems to different conditions in both health and disease. Therefore, the identification, quantification, and spatial mapping of proteoforms are critical to understanding biological processes.

Mass-spectrometry-based top-down proteomics is a powerful tool for proteoform characterization. ${ }^{[4]}$ This approach enables the identification of intact proteoforms based on their mass-to-charge ratio $(\mathrm{m} / \mathrm{z})$ and fragmentation pattern. ${ }^{[5]}$ Topdown proteomics has been used for the identification of thousands of proteoforms in biological samples. ${ }^{[6-13]}$ Several databases have been developed as a community resource for proteoform identification. ${ }^{[14][15][16]}$ Several studies used top-down proteomics for the discovery of disease biomarkers. ${ }^{[17]}$ For example, differences in the expression levels of several KRAS proteoforms have been associated with cancer cell proliferation. ${ }^{[18]}$ In another study, the phosphorylated cardiac troponin I was identified as a potential biomarker of chronic heart failure. ${ }^{[19]}$

Although top-down proteomics is an established field, mapping of the proteoform localization in tissues is still challenging. Mass spectrometry imaging (MSI) is a label-free approach for the untargeted analysis of biomolecules with little sample preparation, which is ideally suited for spatial proteomics studies. MSI may be used for determining the spatial localization of multiple proteoforms in a single experiment, making it a powerful discovery tool for biological research.

Matrix-assisted laser desorption ionization (MALDI) has been used for imaging of intact proteins smaller than $22 \mathrm{kDa}$. [20][21] Although a majority of these studies were performed with a moderate spatial resolution of $50 \mu \mathrm{m}$, a subcellular spatial resolution has been achieved using transmission-geometry MALDI source. ${ }^{[22]}$ Despite these developments, the low charge states of ions generated in MALDI presents a challenge to the detection of proteins using commercial mass spectrometers and their identification using top-down tandem mass spectrometry (MS/MS). ${ }^{[23]}$ The latter limitation has been addressed by combining MALDI MSI with the off-line protein identification using conventional top-down approaches. ${ }^{[4][25]}$ Alternatively, on-tissue protein digestion combined with bottom-up proteomics has been used for protein imaging. ${ }^{[26]}$ Nanodroplet processing in one pot for trace samples (nanoPOTs) ${ }^{[27]}$ is an emerging bottom-up technique that does not require on-tissue digestion. NanoPOTS using laser capture microdissection (LCM) enables imaging and identification of proteins in tissue sections with a spatial resolution of 50-100 $\mu \mathrm{m} .{ }^{[28]}$

Ambient ionization-based on liquid extraction generate higher charge states of protein ions making these techniques suitable for conducting top-down proteomics for proteoform mapping directly from a tissue sample. Desorption electrospray ionization (DESI) and liquid extraction surface analysis (LESA) have been used for detecting intact proteins in tissues. ${ }^{[29]}$ DESI has been used for imaging of $<20 \mathrm{kDa}$ proteins with a spatial resolution of 150-200 $\mu \mathrm{m} .{ }^{[30][31]}$ Meanwhile, the localization of larger proteins and protein complexes of up to $47 \mathrm{kDa}$ has been examined using LESA with a spatial resolution of $600 \mu \mathrm{m} .{ }^{[32][33]}$

Nanospray desorption electrospray ionization (nano-DESI) is an ambient ionization technique, which has been extensively used for imaging of lipids and metabolites with high sensitivity and a spatial resolution down to $10 \mu \mathrm{m} .{ }^{[34]}$ Although the utility of nanoDESI for protein analysis has been demonstrated ${ }^{[35]}$, only a few studies used it for protein imaging. In particular, nano-DESI MSI has been used for protein localization in healthy and MYCinduced lymphomas mouse brain tissue sections ${ }^{[36]}$, imaging of proteins in skin melanoma, ${ }^{[37]}$ and native $\mathrm{MSI}$ of protein complexes in rat kidney tissues. ${ }^{[38][39]}$ 
Despite the impressive developments in spatial proteomics, the direct imaging and identification of proteoforms has not advanced significantly in recent years. In this study, we utilize nano-DESI MSI combined with top-down proteomics directly on a tissue for imaging of proteoforms. Proof-of-concept experiments presented in this study used rat brain tissue sections to demonstrate the ability of nano-DESI MSI to generate high-quality proteoform-specific imaging data. Proteoforms with unique PTMs were selected to generate ion images. We observed forty proteoforms of nineteen $<19 \mathrm{kDa}$ proteins, among which we identified fifteen proteoforms with confidence level 1, nine proteoforms with confidence level $2 \mathrm{~A}$, one proteoform with confidence level 3 and ten proteoforms with confidence level $4 .{ }^{[40]}$ Using proteoforms of the $14.1 \mathrm{kDa}$ myelin basic protein (MBP) as an example, we provide first insights into the differences in proteoform expression levels in different regions of the brain, which is important for understanding the relevant biological pathways.

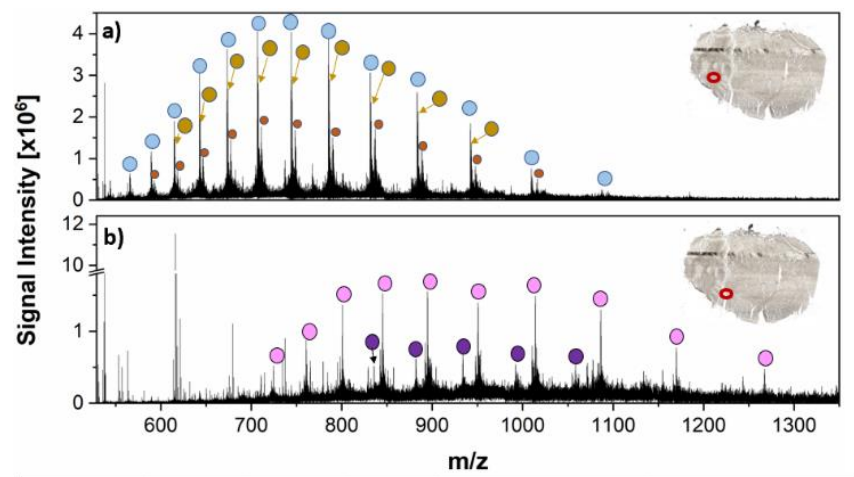

\begin{tabular}{|c|c|c|c|c|c|}
\hline c) & $\bullet$ & $\bullet$ & $\bullet$ & $\bullet$ & $\bullet$ \\
\hline Protein & MBP & MBP & MBP & $\begin{array}{c}\text { Hemoglobin subunit } \\
\text { alpha }\end{array}$ & $\begin{array}{c}\text { Hemoglobin subunit } \\
\text { beta-1 or beta-2 }\end{array}$ \\
\hline Mass/Da & 14,121 & 14,136 & 14,200 & 15,197 & 15,861 \\
\hline
\end{tabular}

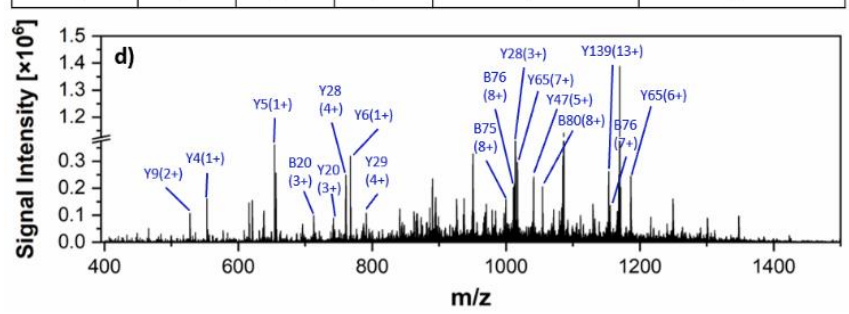

N V LLS A D D KIT NIIIK N ClW G KII G G HIG G ElYIG E]E A LIO G S A Q V K A H G K K V A D A L A K A A D LIPIG ALLISITLL SIDILLH A H K L R V DLP V ILISLH C L LLVLT LLA CLHLHLPLG DLF TLP ALMLHLALS L 125 LDLKLFLLLALS VISLTLVLLLTLSLK Y R

Figure 1. Average mass spectra of the rat brain tissue showing protein signals in the (a) white mater and (b) blood vessel regions highlighted with red circles in the corresponding optical images. (c) A table summarizing the features labeled in a) and b). (d) MS/MS spectrum of the unmodified hemoglobin subunit alpha (HBA1) and its fragmentation map at 23 NCE. Isolation window: $3 \mathrm{~m} / \mathrm{z}$.

Nano-DESI MSI experiments and on-tissue top-down proteomics are described in detail in the supporting information (SI). Briefly, rat brain tissue sections were delipidated by sequential washes in the ethanol solutions $(70 \%, 90 \%$, and $100 \%)$ and chloroform right before the analysis. Proteoforms were extracted into the liquid bridge formed between two fused capillaries and ionized by electrospray ionization at a mass spectrometer inlet. $\mathrm{ACN} / \mathrm{H}_{2} \mathrm{O} / \mathrm{CH}_{3} \mathrm{COOH}(65 / 34 / 1$, v/v/v) was used as the extraction solvent. On-tissue top-down proteomics analysis was performed using targeted MS/MS. Proteoforms were identified by matching their intact masses and MS/MS data against the Rattus norvegicus (Rat: Taxon 10116) database.

Representative mass spectra from two regions of the brain tissue are shown in Figure 1. The 14.1 kDa MBP is the most abundant species detected in the white matter region of the cerebellum (Figure 1a). We observe the unmodified $14.1 \mathrm{kDa}$ MBP and 10 PTMs with the charge state distribution in the range of +15 to +26 . The most abundant proteoforms and their intact masses are listed in Figure 1c. We also detected an $18.4 \mathrm{kDa}$ isoform of MBP and its two PTMs in the white matter region. In addition to MBPs, we observe abundant signals of hemoglobin proteoforms in the blood vessel region (Figure 1b). The mass spectrum obtained for this region contains the charge state distribution of hemoglobin subunit alpha (HBA1), subunit beta-1 (HBB1), and beta-2 (HBB2) with a total of 13 proteoforms in the range of +11 to +20 . The top two most abundant proteoforms are listed in Figure 1c. Figure 1d shows the annotated MS/MS spectrum of the unmodified HBA1 and its corresponding fragmentation map with $41 \%$ sequence coverage. Most of the other proteoforms detected in this study are enhanced in the hippocampal formation region. A representative averaged mass spectrum obtained from this region is shown in Figure S2. A complete list of the proteoforms identified and imaged in this study with their proteoform identification levels is provided in the supporting table. ${ }^{[40]}$ Top-down MS/MS data for all the proteoforms with levels 1, 2A and 3 identifications are shown in Figures S13S36. MS/MS spectra for proteoforms with level 4 identification are shown in Figures S37-S46.

Ion images of several abundant proteoforms normalized to the total ion current (TIC) are shown in Figure 2. Additional images are provided in Figure S3. Ion images of the same proteoforms obtained in replicate experiments are shown in Figures S4 and S5. The two most abundant proteoforms of hemoglobin, unmodified HBA1 (Figure 2b) and dimethylated
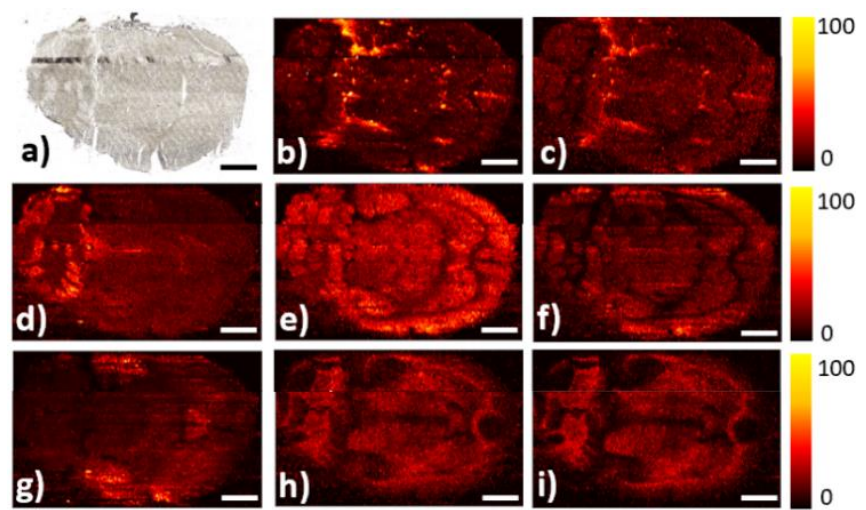

Figure 2. (a) An optical image of an axial rat brain tissue section after nanoDESI MSI analysis. Ion images of the intact proteins normalized to TIC: (b) $m / z$ $894.9384^{17+}, 15,197 \mathrm{Da}$, Hemoglobin subunit alpha (HBA1), unmodified (level 1), (c) $m / z 992.281^{16+}, 15,861 \mathrm{Da}$, Hemoglobin subunit beta-1 (HBB-1), R104 dimethylation (level 1), (d) $m / z 765.4067^{13+}, 9,937 \mathrm{Da}$, Acyl-CoA-binding protein (ACBP), acetylation (level 2A), (e) $\mathrm{m} / z 784.564^{7+}, 5,485 \mathrm{Da}$, Cytochrome c oxidase subunit 7c, mitochondrial (COX7c), unmodified (level 1), (f) $\mathrm{m} / \mathrm{z}$ 998.7947 ${ }^{10+}, 9,978 \mathrm{Da}$, Cytochrome c oxidase subunit 6B1 (COX6B1), Nterminal acetylation (level 1), (g) $\mathrm{m} / \mathrm{z} 709.9375^{7+}, 4,963 \mathrm{Da}$, Thymosin beta-4, acetylation (level 2A), (h) $m / z 741.8094^{19+}, 14,075 \mathrm{Da}$, myelin basic protein (MBP), unmodified (level 1), (i) $\mathrm{m} / z 682.3572^{27+}, 18,397 \mathrm{Da}$, myelin basic protein (MBP), N-terminal acetylation (level 1). Scale bar: $3 \mathrm{~mm}$. 
HBB-1 (Figure 2c) are enhanced in the blood vessel region. Similar localization is observed for all the hemoglobin proteoforms The observed localization of hemoglobin proteoforms to the blood vessel region validates the proteoform-selective imaging experiments. Additional ion images of hemoglobin in replicate experiments are shown in Figures S10, S11, and S12.

Figure $2 d$ shows the unique distribution of the acetylated acyl-CoA binding protein (ACBP) enhanced in the grey matter region of the rat brain cerebellum. ACBP functions as a transporter of both medium- and long-chain acyl-CoA esters. The observed enhancement of the ACBP in the grey matter is consistent with its previously reported localization to the glial cells and synaptosomal nerve ending, the major components of the grey matter in rat brain. ${ }^{[41]}$ Both the unmodified mitochondrial cytochrome c oxidase, subunit $7 c$ (Figure 2e) and N-terminal acetylated cytochrome c oxidase 6B1 (Figure 2f) are evenly distributed across the rat brain tissue. Figure $2 \mathrm{~g}$ displays the localization of the acetylated $4.9 \mathrm{kDa}$ thymosin beta- 4 , which is enhanced in the hippocampal formation, isocortex, lateral spetal nucles, and striatum ventral regions. This distribution is consistent with the high expression level of thymosin beta-4 messenger RNA (mRNA) in the hippocampal formation and cerebral cortex regions. ${ }^{[42][43]} \mathrm{A}$ similar localization is observed for the acetylated $4.7 \mathrm{kDa}$ isoform of thymosin beta-4 (Figure S4t).
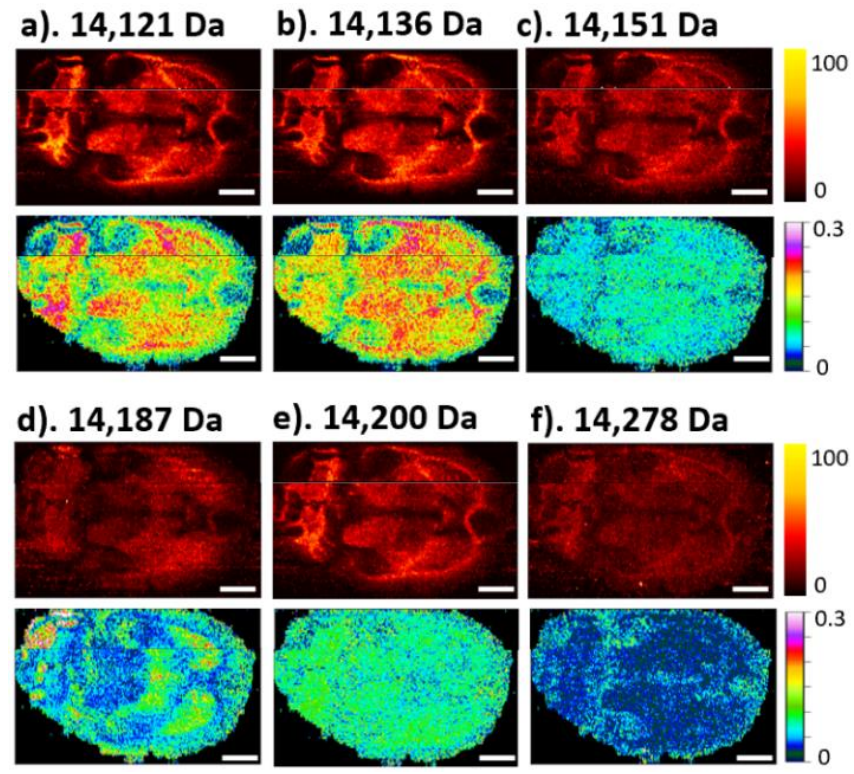

Figure 3. Ion images of the +19 charge state of the $14.1 \mathrm{kDa}$ MBP proteoforms Top panels show ion images normalized to the TIC. Bottom panels show images generated by plotting the ratio of the individual proteoform signal to the sum of signals of all the MBP proteoforms: (a) $\mathrm{m} / \mathrm{z} 744.2335^{19+}, 14,121 \mathrm{Da}$, N-terminal acetylation (level 1), (b) $\mathrm{m} / \mathrm{z} 745.0235^{19+}, 14,136 \mathrm{Da}, \mathrm{N}$-terminal acetylation, methionine sulfoxide (level 1), (c) $m / z 745.8132^{19+}, 14,151 \mathrm{Da}$, phosphorylation (level 3), (d) $m / z 747.7063^{19+}, 14,187 \mathrm{Da}$, dimethylation, phosphorylation (level 2A), (e) $m / z 748.3901^{19+}, 14,200 \mathrm{Da}, \mathrm{N}$-terminal acetylation, phosphorylation (level 2A), (f) $m / z \quad 752.4923^{19+}, 14,278 \mathrm{Da}, \mathrm{N}$-terminal acetylation, diphosphorylation (level $2 \mathrm{~A}$ ). Scale bar: $3 \mathrm{~mm}$.

Ion images of the two isoforms of MBP, unmodified $14.1 \mathrm{kDa}$ MBP and N-terminal acetylated $18.4 \mathrm{kDa}$ MBP (Figure $2 \mathrm{~h}, 2 \mathrm{i}$ ), indicate a similar localziation of these two proteins in rat brain tissue. The signals of MBPs are enhanced in midbrain and white matter regions of the brain. MBPs are abundant proteins in the myelin sheath essential for the formation of myelin and associated with protein transport and signaling. ${ }^{[44][45]}$

MBP and hemoglobin are the two proteins with most PTMs detected in this study. A region of the mass spectrum containing the +19 charge state of $14.1 \mathrm{kDa}$ MBP proteoforms and +25 charge state of $18.4 \mathrm{kDa}$ MBP proteoforms is shown in Figure S6. Figure 3 shows ion images of six MBP proteoforms. Ion images of all the eleven MBP proteoforms are shown in Figure S7. Additional ion images obtained in replicate experiments are shown in Figure S8 and S9 to demonstrate reproducibility. All the proteoforms have similar spatial distributions, which is consistent with the expression of their coding genes in specific regions. However, the relative abundances of different proteoforms vary across the tissue. These differences are visualized using ratio images shown under each ion image in Figure 3 . The ratio images were generated by plotting the ratio of the individual proteoform signal to the sum of signals of all the MBP proteoforms in the +19 charge state in each pixel of the image. The ratio images reveal the expression of each proteoform in different regions of the brain tissue.

Both the N-terminal acetylated MBP (Figure 3a) and its oxidized form (Figure $3 b$ ) are enhanced in the midbrain and white matter regions. However, the $\mathrm{N}$-terminal acetylated MBP (Figure $3 a$ ) is more abundant in the white matter of the cerebellum region whereas the oxidized form is more abundant in the midbrain region (Figure $3 \mathrm{~b}$ ). Methionine oxidation is a spontaneous PTM attributed to oxidative damage, which accumulates with aging. ${ }^{[46]}$ Methionine sulfoxide reductase (MSR) repairs the oxidative damage by reducing methionine sulfoxide to methionine. ${ }^{[46]}$ This observed difference in the relative abundance of the two proteoforms may be attributed to the higher activity of MSR in the cerebellum region in comparison with other regions of the brain. ${ }^{[47]}$

The ratio images of the phosphorylated MBP (Figure 3c) and its $\mathrm{N}$-terminal acetylated form (Figure $3 \mathrm{e}$ ) display a uniform distribution across the entire tissue section. However, the ratio image of the $\mathrm{N}$-terminal acetylated, di-phosphorylated MBP (Figure $3 f$ ) shows the enhanced abundance of this proteoform in the hippocampal formation and isocortex regions. An interesting ratio image showing an enhanced abundance in the thalamus and striatum ventral region was observed for the dimethylated, phosphorylated MBP (Figure 3d).

In summary, the combination of on-tissue top-down proteomics with nano-DESI MSI has been used to generate first proteoform-selective images of a rat brain tissue. We obtained spatial maps of forty proteoforms of nineteen distinct proteins with twenty-five proteoforms identified with confidence levels $1,2 \mathrm{~A}$ and 3. Ratio images reveal the differential expression of the individual proteoforms in different parts of the tissue. Although this proof-of-concept study focused on proteoforms of abundant proteins, the observed differential proteoform localization in tissue sections demonstrates the power of this approach for studying the state of different cell types in biological tissues. Several strategies may be used to improve the detection of a broader range of proteoforms. These include spectral deconvolution ${ }^{[48][49][50]}$, coupling of nano-DESI MSI with ion mobility separation ${ }^{[39][51]}$, and single ion detection ${ }^{[52][53]}$. Furthermore, sequence coverage in topdown identification experiments may be improved by improving the signals and using complementary fragmentation approaches such as electron transfer dissociation (ETD). ${ }^{[54][55][56]}$ Proteoformselective imaging opens opportunities for mapping of differentially modified proteoforms to functional units within tissues. As the 
technology is pushed toward the single cell level, the exploration of proteoforms in specific cell types in human tissues will be possible, thus advancing our understanding of proteoform function and their exploitation as disease biomarkers.

\section{Acknowledgements}

The authors gratefully acknowledge the financial support from the National Institutes of Health (NIH) Common Fund, through the Office of Strategic Coordination/Office of the NIH Director under awards UG3HL145593 and UH3CA255132 (HuBMAP Program, JL), UH3CA246635 (HuBMAP Program, NLK), and P41GM108569 (NLK), and the support from National Science Foundation (NSF) under awards \#1916691 (Center for Bioanalytic Metrology, JL). MSI data analysis tools used in this study were developed with support from NSF-180813 and NSF2108729 (JL). We thank Drs. Elizabeth K. Neumann and Jeffrey M. Spraggins (Vanderbilt University) for providing rat brain tissue sections.

Keywords: proteoforms • post-translational modifications • ontissue top-down proteomics $\cdot$ mass spectrometry imaging

[1] R. Aebersold, J. N. Agar, I. J. Amster, M. S. Baker, C. R. Bertozzi, E. S. Boja, C. E. Costello, B. F. Cravatt, C. Fenselau, B. A. Garcia Y. Ge, J. Gunawardena, R. C. Hendrickson, P. J. Hergenrother, C. G. Huber, A. R. Ivanov, O. N. Jensen, M. C. Jewett, N. L. Kelleher, L. L. Kiessling, N. J. Krogan, M. R. Larsen, J. A. Loo, R. R. Ogorzalek Loo, E. Lundberg, M. J. Maccoss, P. Mallick, V. K. Mootha, M. Mrksich, T. W. Muir, S. M. Patrie, J. J. Pesavento, S. J. Pitteri, H. Rodriguez, A. Saghatelian, W. Sandoval, H. Schlüter, S. Sechi, S. A. Slavoff, L. M. Smith, M. P. Snyder, P. M. Thomas, M. Uhlén, J. E. Van Eyk, M. Vidal, D. R. Walt, F. M. White, E. R. Williams, T. Wohlschlager, V. H. Wysocki, N. A. Yates, N. L. Young, B. Zhang, Nat. Chem. Biol. 2018, 14, 206-214.

[2] L. M. Smith, N. L. Kelleher, Nat. Methods 2013, 10, 186-187.

[3] R. B. Parekh, C. Rohlff, Curr. Opin. Biotechnol. 1997, 8, 718-723.

[4] F. Lermyte, Y. O. Tsybin, P. B. O'Connor, J. A. Loo, J. Am. Soc. Mass Spectrom. 2019, 30, 1149-1157.

[5] N. Siuti, N. L. Kelleher, Nat. Methods 2007, 4, 817-821.

[6] E. N. Mccool, R. A. Lubeckyj, X. Shen, D. Chen, Q. Kou, X. Liu, L. Sun, Anal. Chem. 2018, 90, 5529-5533.

[7] J. C. Tran, L. Zamdborg, D. R. Ahlf, J. E. Lee, A. D. Catherman, K. R. Durbin, J. D. Tipton, A. Vellaichamy, J. F. Kellie, M. Li, C. Wu, S. M. M. Sweet, B. P. Early, N. Siuti, R. D. Leduc, P. D. Compton, P. M. Thomas, N. L. Kelleher, Nature 2011, 480, 254-258.

[8] M. Dupré,Dupré, M. Duchateau, C. Malosse, D. Borges-Lima, V. Calvaresi, I. Podglajen, D. Clermont, M. Rey, J. Chamot-Rooke, J. Proteome Res. 2020, 20, 202-211.

[9] M. Zhou, N. Uwugiaren, S. M. Williams, R. J. Moore, R. Zhao, D. Goodlett, Y. Zhu, Anal. Chem. 2020, 92, 7087-7095.

[10] D. Yu, Z. Wang, K. A. Cupp-Sutton, Y. Guo, Q. Kou, K. Smith, X Liu, S. Wu, J. Am. Soc. Mass Spectrom. 2021, 32, 1336-1344.

[11] M. R. Mehaffey, Q. Xia, J. S. Brodbelt, Anal. Chem. 2020, 92, 15202-15211.

[12] L. V. Schaffer, L. C. Anderson, D. S. Butcher, M. R. Shortreed, R. M. Miller, C. Pavelec, L. M. Smith, J. Proteome Res. 2021, 20, 317-
325.

[13] N. D. Schmitt, J. M. Berger, J. B. Conway, J. N. Agar, Anal. Chem 2021, 93, 6355-6362.

[14] Y. Dai, K. E. Buxton, L. V Schaffer, R. M. Miller, R. J. Millikin, M. Scalf, B. L. Frey, M. R. Shortreed, L. M. Smith, J. Proteome Res. 2019, 18, 3671-3680.

[15] J. Park, P. D. Piehowski, C. Wilkins, M. Zhou, J. Mendoza, G. M. Fujimoto, B. C. Gibbons, J. B. Shaw, Y. Shen, A. K. Shukla, R. J. Moore, T. Liu, V. A. Petyuk, N. Tolić, L. Paša-Tolić, R. D. Smith, S. H. Payne, S. Kim, Nat. Methods 2017, 14, 909-914.

[16] C. Lantz, M. A. Zenaidee, B. Wei, Z. Hemminger, R. R. Ogorzalek Loo, J. A. Loo, J. Proteome Res. 2021, 20, 1928-1935.

[17] L. Smith, J. Agar, J. Chamot-Rooke, P. Danis, Y. Ge, J. Loo, L. Pasa-Tolic, Y. Tsybin, N. Kelleher, 2020, DOI 10.20944/PREPRINTS202010.0368.V1.

[18] I. Ntai, L. Fornelli, C. J. Dehart, J. E. Hutton, P. F. Doubleday, R. D. Leduc, A. J. Van Nispen, R. T. Fellers, G. Whiteley, E. S. Boja, H. Rodriguez, N. L. Kelleher, PNAS 2018, 115, 4140-4145.

[19] J. Zhang, M. J. Guy, H. S. Norman, Y.-C. Chen, Q. Xu, X. Dong, H. Guner, S. Wang, T. Kohmoto, K. H. Young, R. L. Moss, Y. Ge, J. Proteome Res. 2011, 10, 4054-4065.

[20] B. M. Prentice, D. J. Ryan, R. Van De Plas, R. M. Caprioli, J. M Spraggins, Anal. Chem. 2018, 90, 5090-5099.

[21] R. M. Caprioli, J. Biomol. Tech. 2019, 30, 7-11.

[22] A. Zavalin, J. Yang, K. Hayden, M. Vestal, R. M. Caprioli, Anal. Bioanal. Chem. 2015, 407, 2337-2342.

[23] D. J. Ryan, J. M. Spraggins, R. M. Caprioli, Curr. Opin. Chem. Biol. 2019, 48, 64-72.

[24] D. J. Ryan, N. H. Patterson, N. E. Putnam, A. D. Wilde, A. Weiss, W. J. Perry, J. E. Cassat, E. P. Skaar, R. M. Caprioli, J. M. Spraggins, Anal. Chem. 2019, 91, 7578-7585.

[25] H. Ye, R. Mandal, A. Catherman, P. M. Thomas, N. L. Kelleher, C. Ikonomidou, L. Li, PLoS One 2014, 9, e92831.

[26] B. Cillero-Pastor, R. M. A. Heeren, J. Proteome Res. 2013, 13, 325 335.

[27] Y. Zhu, P. D. Piehowski, R. Zhao, J. Chen, Y. Shen, R. J. Moore, A. K. Shukla, V. A. Petyuk, M. Campbell-Thompson, C. E. Mathews, R. D. Smith, W.-J. Qian, R. T. Kelly, Nat. Commun. 2018, 9, 882.

[28] P. D. Piehowski, Y. Zhu, L. M. Bramer, K. G. Stratton, R. Zhao, D. J. Orton, R. J. Moore, J. Yuan, H. D. Mitchell, Y. Gao, B. J. M. WebbRobertson, S. K. Dey, R. T. Kelly, K. E. Burnum-Johnson, Nat. Commun. 2020, 11, 1-12.

[29] R. L. Griffiths, K. I. Kocurek, H. J. Cooper, Curr. Opin. Chem. Biol. 2018, 42, 67-75.

[30] M. W. Towers, T. Karancsi, E. A. Jones, S. D. Pringle, E. Claude, J. Am. Soc. Mass Spectrom. 2018, 29, 2456-2466.

[31] K. Y. Garza, C. L. Feider, D. R. Klein, J. A. Rosenberg, J. S. Brodbelt, L. S. Eberlin, Anal. Chem. 2018, 90, 7785-7789.

[32] O. J. Hale, E. K. Sisley, R. L. Griffiths, I. B. Styles, H. J. Cooper, J. Am. Soc. Mass Spectrom. 2020, 31, 873-879.

[33] O. J. Hale, H. J. Cooper, J. Am. Soc. Mass Spectrom. 2020, 31, 2531-2537.

[34] R. Yin, K. E. Burnum-Johnson, X. Sun, S. K. Dey, J. Laskin, Nat. Protoc. 2019, 14, 3445-3470.

[35] P. J. Roach, J. Laskin, A. Laskin, Analyst 2010, 135, 2161-2452.

[36] C. Hsu, P. Chou, R. N. Zare, Anal. Chem. 2015, 87, 11171-11175.

[37] C.-L. Chen, T.-H. Kuo, H.-H. Chung, P. Huang, L.-E. Lin, C.-C. Hsu, 
J. Am. Soc. Mass Spectrom. 2021, 32, 653-660.

[38] O. J. Hale, H. J. Cooper, Anal. Chem. 2021, 93, 4619-4627.

[39] O. J. Hale, J. W. Hughes, H. J. Cooper, Int. J. Mass Spectrom. 2021, 468, 116656

[40] L. M. Smith, P. M. Thomas, M. R. Shortreed, L. V Schaffer, R. T. Fellers, R. D. LeDuc, T. Tucholski, Y. Ge, J. N. Agar, L. C. Anderson, J. Chamot-Rooke, J. Gault, J. A. Loo, L. Paša-Tolić, C. V Robinson, H. Schlüter, Y. O. Tsybin, M. Vilaseca, J. Antonio Vizcaíno, P. O. Danis, N. L. Kelleher, Nat. Methods 2019, 16, 939940

[41] R. E. Gossett, A. A. Frolov, J. B. Roths, W. David Behnke, A. B. Kier, F. Schroeder, Lipids 1996, 31, 895-918.

[42] P. Carpintero, R. Anado'n, A. Anado'n, S. Di'az, D. Di'az-Regueira, J. Go'mez, G. Go'mez-Ma'rquez, M. Ma'rquez, Neuroscience 1999, 90, 1433-1444.

[43] G. H. Zhang, K. D. Murthy, R. Binti Pare, Y. H. Qian, Eur. J. Inflamm. 2020, 18, 1-11.

[44] D. A. Plymire, C. E. Wing, D. E. Robinson, S. M. Patrie, Anal. Chem. 2017, 89, 12030-12038.

[45] J. M. Boggs, Cell. Mol. Life Sci. 2006, 63, 1945-1961.

[46] P. A. C. Cloos, S. Christgau, Biogerontology 2004, 5, 139-158.

[47] E. R. Stadtman, H. Van Remmen, A. Richardson, N. B. Wehr, R. L. Levine, Biochim. Biophys. Acta - Proteins Proteomics 2005, 1703, $135-140$.

[48] T. M. Allison, P. Barran, J. L. P. Benesch, S. Cianferani, M. T. Degiacomi, V. Gabelica, R. Grandori, E. G. Marklund, T. Menneteau, L. G. Migas, A. Politis, M. Sharon, F. Sobott, K. Thalassinos, Anal. Chem. 2020, 92, 10881-10890.

[49] S. P. Cleary, H. Li, D. Bagal, J. A. Loo, I. D. G. Campuzano, J. S. Prell, J. Am. Soc. Mass Spectrom. 2018, 29, 2067-2080.

[50] M. T. Marty, A. J. Baldwin, E. G. Marklund, G. K. A. Hochberg, J. L. P. Benesch, C. V. Robinson, Anal. Chem. 2015, 87, 4370-4376.

[51] D. Unsihuay, R. Yin, D. Mesa, M. Yang, Y. Li, X. Sun, S. K. Dey, J. Laskin, Anal. Chim. Acta 2021, 1186, 339085.

[52] J. O. Kafader, R. D. Melani, K. R. Durbin, B. Ikwuagwu, B. P. Early, R. T. Fellers, S. C. Beu, V. Zabrouskov, A. A. Makarov, J. T. Maze, D. L. Shinholt, P. F. Yip, D. Tullman-Ercek, M. W. Senko, P. D. Compton, N. L. Kelleher, Nat. Methods 2020, 17, 391-394.

[53] J. O. Kafader, K. R. Durbin, R. D. Melani, B. J. Des Soye, L. F. Schachner, M. W. Senko, P. D. Compton, N. L. Kelleher, J. Proteome Res. 2020, 19, 1346-1350.

[54] M. A. Zenaidee, C. Lantz, T. Perkins, W. Jung, R. R. O. Loo, J. A. Loo, J. Am. Soc. Mass Spectrom. 2020, 31, 1896-1902.

[55] L. C. Anderson, C. J. Dehart, N. K. Kaiser, R. T. Fellers, D. F. Smith, J. B. Greer, R. D. Leduc, G. T. Blakney, P. M. Thomas, N. L. Kelleher, C. L. Hendrickson, J. Proteome Res. 2016, 16, 10871096.

[56] N. M. Riley, J. W. Sikora, H. S. Seckler, J. B. Greer, R. T. Fellers, R. D. Leduc, M. S. Westphall, P. M. Thomas, N. L. Kelleher, J. J. Coon, Anal. Chem. 2018, 90, 8553-8560. 
